\title{
BALAI KAMPUNG KOTA KREATIF DI KOTA TUA JAKARTA UTARA
}

\author{
Angy (hasia ${ }^{1)}$, Diah Anggraini ${ }^{2)}$ \\ 1) Program Studi S1 Arsitektur, Fakultas Teknik, Universitas Tarumanagara,angychasianew@gmail.com \\ 2) Program Studi S1 Arsitektur, Fakultas Teknik Universitas Tarumanagara, diaha@ft.untar.ac.id
}

\begin{abstract}
Abstrak
Seiring dengan perkembangan zaman ke Era Generasi Milenial. Kampung kota juga turut berkembang menjadi permukiman yang lebih modern. Warga kampung kota juga sudah mulai mengenal alat elektronik seperti gadget dan smartphone. Permasalahan utama yang terjadi bukanlah hanya pemenuhan kebutuhan akan tempat tinggal, namun bagaimana agar lingkungan tempat tinggal dapat berkembang dan menaikan taraf hidup masyarakatnya. Kebutuhan yang perlu dipenuhi adalah penyediaan lahan pekerjaan (mata pencaharian) dan ruang publik (penghijauan dan rekreasi). Sementara itu kawasan Wisata Kota Tua di Jakarta Utara, yang pertumbuhannya sejak Jaman Kolonial tidak lepas dari pengaruh Kampung Kota, mulai berkembang kearah kawasan wisata yang lebih maju. Kampung Kota secara langsung dan tidak langsung juga menjadi daerah penunjang kegiatan wisata di Kota Tua tersebut. Oleh karena itu, Balai Kampung Kota Kreatif dirancang dengan tujuan untuk mewadahi kegiatan ekonomi kreatif beserta pelatihannya bagi warga kampung kota dan juga sekaligus menjadi tempat wisata bagi turis yang mengunjungi Kawasan Wisata Kota Tua. Menggunakan Metode Cross-DisProgramming, bangunan dirancang dengan menggabungkan dua program utama yaitu zona kegiatan komunitas dan zona wisata. Hasil perancangan yang didapatkan bahwa zona kegiatan komunitas yang dibutuhkan adalah program produksi ekonomi kreatif dalam bidang kayu, kriya, pakaian, dan tanaman, serta program tambahan yaitu ruang bersama, unit usaha, selasar kreatif dan area pengetahuan. Sedangkan untuk zona wisata yang dibutuhkan adalah galeri, teater, dan pusat turis. Program yang dapat menggabungkan antara dua sasaran (warga kampung kota dan turis) adalah ruang luar yang berupa Market Place dan Ampy Theater. Kesimpulan yang didapat pada perancangan Balai Kampung Kota Kreatif adalah keseimbangan antara kegiatan warga kampung kota dan wisatawan Kota Tua Jakarta dapat tercapai dengan dengan cara mewadahi kebutuhan ruang untuk keduanya secara seimbang melalu program-program yang dipilah untuk digabungkan atau didekatkan.
\end{abstract}

Kata Kunci : Komunitas; Kota Tua Jakarta; Warga Kampung Kota; Turis

\begin{abstract}
Along with the current development to the Millennial Generation Era, Kampung Kota also developed into more modern habitations. Residents of Kampung Kota have also begun to recognize electronic devices such as gadgets and smartphones. The main problem that occurs is not only the fulfillment of the need for a place to live, but how to make it possible for the living environment to grow and improve the standard of living of its people. Consequently, the needs that urge to be fulfilled are job (livelihoods) and public space (greening and recreation). Meanwhile, the Old City Tourism area in Jakarta, whose growth since the colonial era was inseparable from the influence of the Kampung Kota, began to develop towards more advanced tourist areas. Kampung Kota directly and indirectly also becomes a supporting area for tourism activities in the Old City. Therefore, Balai Kampung Kota Kreatif was designed with the aim of accommodating creative economic activities and training for Kampung Kota Residents and also for a tourist attraction for Old City Tourists. Using the Cross-Dis Programming Method, the building was designed by combining two main programs, namely the Community Activity Zone and the Tourism Zone. The result of the design showed that the community activity Zone which is needed is a Creative Economic Production Program in the fields of wood, crafts, clothing, and plants, along with additional programs namely Shared Space, Business Units, Creative Corridors and Knowledge areas. Whereas for the Tourist Zones needed are Galleries, Theaters, and Tourist Centers. The program which could combine between two targets (Kampung Kota Residents and Tourist) is the outdoor in the form of Market Place and Ampy Theater. The conclusions obtained from the design of the Balai Kampung Kota Kreatif is a building which could contain a combination of two programs with different targets at once by accommodating the space requirements for both equally.
\end{abstract}

Keywords: Community; Kampung Kota Resident; Kota Tua Jakarta; Tourist 


\section{PENDAHULUAN}

Sejak jaman dahulu (1950an) keberadaan kampung kota tidak lepas dari kehidupan Kota Jakarta. Menurut Abdul Chaer (2018) yang dilansir pada detik.travel.com, kampung sudah ada di Jakarta dan tercipta karena penjajah Belanda yang mendatangkan berbagai suku bangsa ke Batavia saat itu. Kampung Kota, selain membawa dampak negatif bagi citra kota berupa kekumuhan, juga memiliki peran tersendiri bagi kota, yaitu sebagai alternatif area bermukim bagi pendatang dengan biaya yang murah dan dapat menunjang kehidupan warga menengah ke bawah untuk tetap bertahan hidup. Warga kampung kota pun tidak dapat dipandang rendah begitu saja, karena sifat gotong royong dan musyawarah yang tinggi - yang masih ada hingga saat ini, dapat membawa perkembangan yang besar bagi warga dan eksistensi Kampung Kota itu sendiri. Contoh yang terdekat adalah perubahan mindset untuk hidup sehat yang telah dilakukan oleh Kampung Tongkol, Lodan, dan Krapu yang mulai menanam sayur sendiri sebagai bahan baku untuk memasak. Bila kegiatan-kegiatan ini dikembangkan dengan inovatif kreatif, kehidupan pada sebuah kota juga akan berkembang menjadi lebih berkelanjutan. Pada praktiknya, warga Kampung Kota juga memerlukan tenaga ahli untuk membatu dan mengajari mereka cara yang lebih baik dalam hal bermukim, maka dari itu pendekatan juga harus dilakukan secara kolaboratif oleh masyarakat kota, termasuk diantaranya warga kampung kota maupun pihak eksternal yang dapat membantu (akademisi, praktisi, arsitek, LBH, dII)

Asumsi awal dari perancangan Proyek ini fokus pada aspek sosial-ekonomi-teknologi. Ketiga aspek ini harus dijalankan secara seimbang untuk mendapatkan kehidupan yang berkesinambungan bagi warga kota. Aspek sosial berperan untuk memicu rasa gotong royong dan rasa tenggang rasa antar warga kota, aspek ekonomi berperan sebagai penunjang kehidupan warga kota untuk berpenghasilan, dan aspek teknologi berperan untuk menjadi senjata bagi perkembangan yang ingin dicapai bersama.

\section{METODE}

Pada proses perancangan Balai Kampung Kota Kreatif di Kota Tua Jakarta Utara, metode yang digunakan adalah metode perancangan Cross - Dis Programming yang terinspirasi dari ide konsep perancangan milik Bernard Tchumi. Cross-programming; yaitu menggunakan ruang atau konfigurasi spasial yang tidak sesuai dengan program asalnya. Misalnya bangunan ibadah digunakan sebagai klub malam, menempatkan suatu konfigurasi pada lokasi yang tidak berkaitan, atau menempatkan museum di bangunan parkir (Mantiri dan Makainas, 2011). Sedangkan Dis-programming; yaitu menggabungkan dua program agar saling mengganggu. Misalnya menggabungkan supermarket dengan gedung perkantoran (Novielle, 2007). Cross Programming meliputi dua aspek yaitu aktivitas harus bisa tumpang tindih dan bangunan harus mampu beradaptasi dengan program yang berbeda dari waktu ke waktu. Pada perancangan Balai Kampung Kota Kreatif perancangan menggabungkan dua program utama yaitu program untuk komunitas (kampung kota) dan program wisata. Penggabungan antara keduanya melibatkan aktivitas yang tumpang tindih, dapat mempengaruhi kondisi spasial ataupun kegiatan yang bersinggungan. Contohnya adalah dengan menggabungkan area ampy theater dengan food center. Kedua program yang berbeda namun disatukan pada satu zona sehingga menimbulkan keramaian pada saat bersamaan, disebut dengan dis programming.

\section{DISKUSI DAN HASIL}

\section{Hubungan Tipologi - Perilaku Manusia - Arsitektur dan Generasi Milenial}

Tipe dan perilaku saling berhubungan, Tipe mempengaruhi perilaku dan juga sebaliknya. Siapa yang memengaruhi dan dipengaruhi tergantung dari konteks/ aspek yang ada. Keadaan zaman dan kondisi tertentu juga dapat mempengaruhi hubungan antara tipe dan perilaku tersebut, khususnya dalam bidang arsitektur. Dalam arsitektur sebuah tipe dalam desain dapat memengaruhi seluruh bentuk bangunan pada jaman tersebut dan pada akhinya membentuk perilaku masyarakatnya. Generasi milenial banyak memberikan dampak pada 
perkembangan dan perubahan jaman diberbagai bidang, seperti kesehatan, ekonomi, politik, dan juga arsitektur. Perubahan-perubahan tersebut didasari oleh pola hidup generasi ini yang berbeda dari generasi sebelumnya. Akibatnya gebrakan-gebrakan dalam menjalani hidup tersebut melahirkan sebuah kebiasaan baru yang cepat meluas tersebar kepada masyarakat kota, bahkan dunia.

Pada era kejayaan gerenasi milenial bentuk arsitektur juga berkembang seperti munculnya istilah 'Rumah Tipe Minimalis' yang sempat menjadi tren di perkotaan. Gaya merancang dan tipe yang lahir hampir mirip diberbagai lokasi. Banyak juga perubahan yang terjadi pada penggunaan material pada rumah, seperti penggunaan kayu pada kuda-kuda atap pelana yang berubah menjadi rangka baja, yang berpengaruh pada penekanan budget pembangunan.

Melihat fenomena ini kita tersadar bahwa bentuk-bentuk baru ini adalah citra guna yang baru (pada masanya). Kata citra dapat berarti gambaran, yang bila dikaitkan dengan arsitektur dapat berarti estetika, sedangkan guna, sangat terlihat jelas dari fungsi yang ditimbulkan akibat inovasi-inovasi yang diciptakan oleh generasi milenial. Maka dari itu, jelas terlihat bahwa tipologi dan perilaku yang saling berhubungan, berhubungan erat juga dengan citra dan guna pada zaman tertentu, termasuk era generasi milenial.

\section{Generasi Milenial di Kampung Kota}

Generasi milenial pada kampung kota juga membawa dampak perubahan besar. Generasi ini merupakan pembawa segala macam teknologi dan modernitas akibat globalisasi. Setiap perkembangan yang terjadi pada jaman ini merupakan hasil dari berevolusinya Generasi $X$ ke Generasi $Y$ yang perilaku hidupnya membawa dampak juga pada lingkungan dan kota. Arsitektur kampung kota pun berubah seiring dengan berembangnya generasi ini. Sebagai contoh konkrit adalah banyak diantara Kampung Kota yang berada di Indonesia mengalami perkembangan yang pesat, bahkan perubahan yang cukup signifikan dalam hal arsitektur. Contohnya adalah mulai hilangnya rumah panggung bermaterial bambu, digantikan dengan rumah bata dengan semen, cara hidup yang sudah memerhatikan kebersihan lingkungan demi kelanjutan hidup bermukim dikota, dan masih banyak lagi.
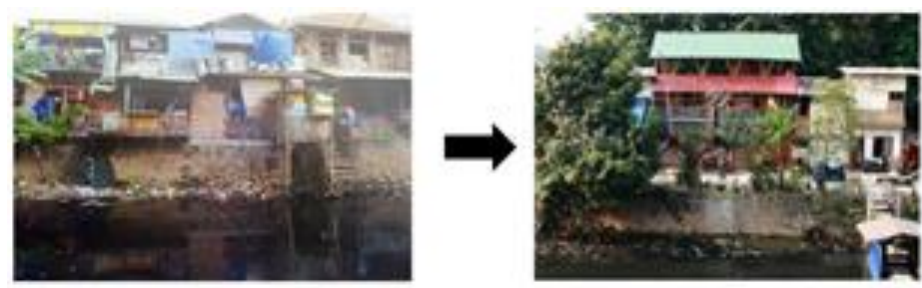

Gambar 1. Perubahan Kampung Tongkol 1900-an dan 2016 Sumber : BBC.com, 2016

Contoh yang kedua terjadi adalah Kampung Jodipan yang sekarang dikenal dengan nama Kampung Pelangi di Malang. Sebuah gerakan untuk mengecat kampung, menjadikan kampung Jodipan menjadi kampung wisata, yang pada akhirnya meningkatkan perekonomian dan kesejahteraan hidup Warga Kampung Jodipan sendiri.

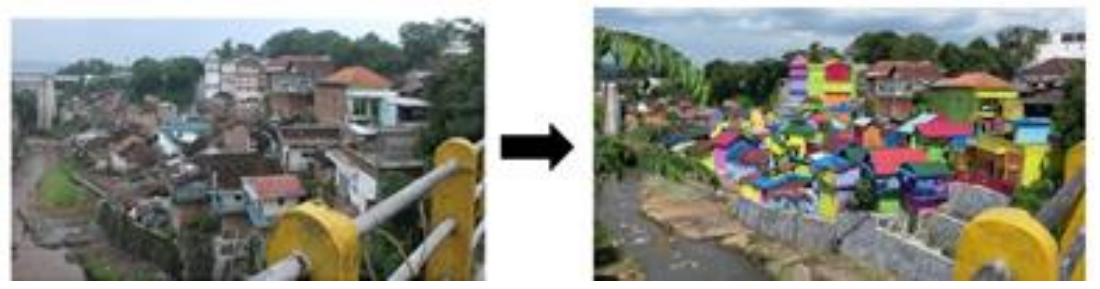

Gambar 2. Kampung Jodipan sebelum dan sesudah diwarnai Sumber : idntimes.com, 2015 
Semua inovasi dan kreativitas yang terjadi adalah ide generasi milenial. Beberapa preseden menunjukan bahwa gagasan generasi milenial yang diwujudkan, akan membawa dampak bagi permukiman dan kota.

\section{Tipologi dan Behaviour di Kampung Kota}

Kampung kota, walaupun terkesan kumuh, kotor, ataupun jorok, tetap miliki bagiannya sendiri didalam kota. Kampung kota menjadi wadah tempat bermukim warga kota yang umumnya memiliki penghasilan rendah sebagai dampak meningkatkan urbanisasi. Maka kampung kota perlu didefinisikan sebagaimana dengan fungsinya yang sebenarnya. Kampung kota yang terbentuk sampai era ini - mungkin telah berubah dari kampung kota pada jaman kolonial. Namun, bentuk-bentuk tersebut menghasilkan sebuah tipologi baru yang akan terus berubah dan berkembang. Seperti yang ditulis pada buku 100 Kompendium Kampung Kota oleh RUJAK RCUS, bahwa arsitektur terbentuk dan dibentuk oleh warga kampung itu sendiri, maka aktifitas dan perilaku (behavior) dari warga kampung kota akan berpengaruh kepada bentuk kampung ota tempat mereka tinggal. Mencari tipe arsitektur dalam kampung tidak lepas dari usaha untuk mencari strukturnya, lewat bagaimana sebuah hubungan antar elemen kampung terbentuk dan memiliki sifat berkelanjutan. Hubungan yang berkelanjutan tersebut bisa lewat kondisi sosial didalamnya, latar belakang budaya, alam, dan juga kebiasaan penghuni kampung tersebut (Simone, 2010).

Terdapat tiga elemen yang menjadi objek utama observasi tipologi kampung kota oleh RUJAK RCUS, 2018, yaitu elemen fisik, aktifitas tetap, dan Sirkulasi. Ketiga elemen tersebut menjadi dasar sudut pandang untuk melihat aktivitas dan manusia yang dihadapi oleh kampung kota sehingga menghasilkan tipologinya pada jaman ini.
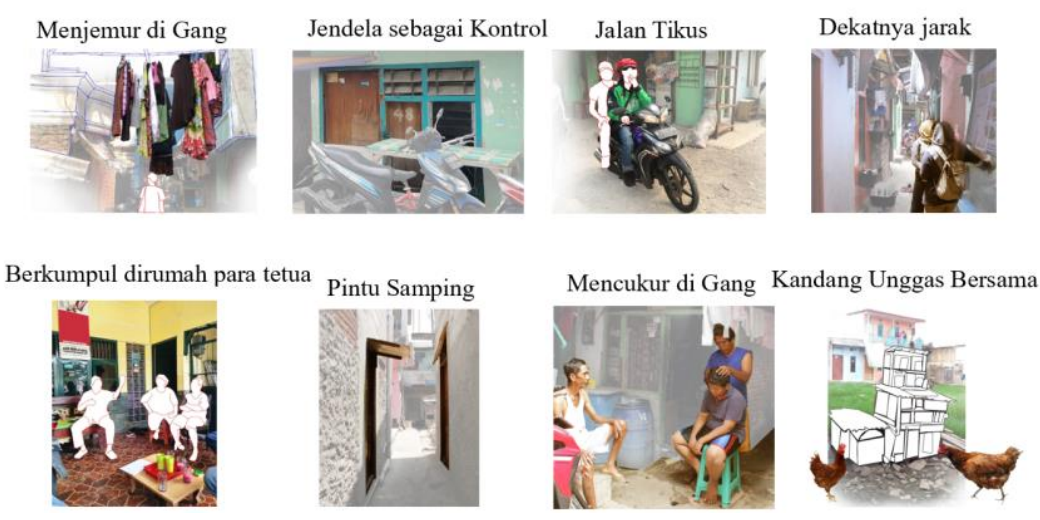

Gamber 3. Tipologi Kampung Kota

Sumber : 100 Kompendium Kampung Kota Jakarta, 2018

\section{Munculnya Komunitas di Kampung Kota dan Perkembangannya di Era Milenial}

Para ahli mencoba menjabarkan definisi mengenai komunitas, salah satunya juga adalah Soerjono Soekanto (2002), menurutnya istilah community dapat diterjemahkan sebagai "masyarakat setempat", atau antaralain merujuk kepada warga-warga sebuah kota, suku, atau suatu bangsa. Apabila anggota-anggota suatu kelompok baik itu kelompok besar atupun kecil, hidup bersama sedemikian rupa sehingga mereka merasakan bahwa kelompok tersebut dapat memenuhi kepentingan hidup yang utama, maka kelompok tadi dapat disebut masyarakat setempat. Intinya mereka menjalin hubungan sosial (social relationship). Pengertian tersebut dapat digunakan sebagai dasar pengertian untuk komunitas pada kampung kota. Seiring berkembangnya zaman, Komunitas di kampung kota tumbuh dan berkembang. Komunitaskomunitas tersebut terbentuk atas beberapa faktor. Menurut Crow dan Allan (1995), Komunitas dapat terbentuk atas dasar dua alasan, yaitu : 
a. Berdasarkan lokasi atau tempat sebuah komunitas dapat dilihat sebagai tempat dimana sekumpulan orang mempunyai sesuatu yang sama secara geografis.

b. Berdasarkan minat sekelompok orang yang mendirikan suatu komunitas karena mempunyai ketertarikan dan minat yang sama, misalnya agama, pekerjaan, suku, ras, maupun berdasarkan kelainan seksual.

Terdapat berbagai macam variasi komunitas yang terdapat di kampung kota. Komunitaskomunitas ini terbentuk biasanya didasari atas pemikiran yang sama, dan keinginan untuk bersama-sama mencapai tujuan tertentu. Bila dikaitkan dengan pendapat Darrunduno (2007) mengenai pentingnya modal ssosial di dalam pertumbuhan sebuah Kampung Kota, komunitas merupakan salah satu alternatif usaha dalam mewujudkan terbentuknya modal sosial yang konkrit. Beberapa aturan menurut Vania Delobelle yang dimiliki komunitas, antara lain :

a. Saling berbagi : Mereka saling menolong dan berbagi satu sama Lain dalam komunitas.

b. Komunikasi : Mereka saling respon dan komunikasi satu sama lain.

c. Kejujuran : Dilarang keras berbohong. Sekali seseorang berbohong, maka akan segera ditinggalkan.

d. Transparansi : Saling bicara terbuka dan tidak boleh menyembunyikan sesuatu hal

e. Partisipasi : Semua anggota harus disana dan berpartisipasi pada acara bersama komunitas

Ketika ke-5 aturan tersebut dapat terpenuhi, kegiatan-kegiatan pada komunitas baru dapat terjadi. Komunitas yang aktif dapat membentuk inisiatif yang akhirnya membawa perubahan, contoh yang terjadi adalah Komunitas Bunga pada Kampung Rawa belong.

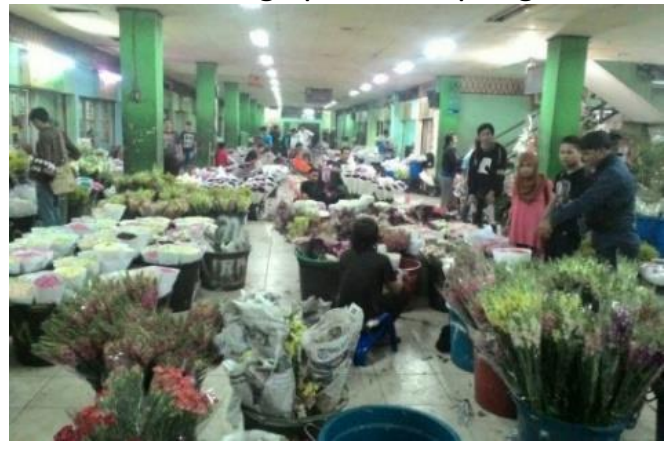

Gambar 4. Komunitas Bunga di Rawa Belong Sumber: Tigapilarnews.com, 2015

Para petani pun kemudian menjual bunga hasil panenannya di pinggiran Jalan Palmerah. Rawabelong seiring berjalannya waktu menjadi sebuah sistem ekonomi yang menghubungkan kota dan wilayah. Bila seseorang ingin mencari bunga, jawaban pertama yang mungkin terlintas adalah membeli dari wilayah Rawabelong. Komunitas Rawa Belong terbentuk akibat potensi wilayah. Fenomena ini menunjukan bahwa suatu komunitas yang terbentuk, dapat memberikan manfaat yang besar pada wilayah disekitarnya, bahkan sampai meluas ke skala kota.

Satu contoh selanjutnya adalah Komunitas Anak Kali Ciliwung. Komunitas ini terbentuk pada tiga kampung yang berdekatan, di bantaran Sungai Ciliwung, yaitu Kampung Krapu, Kampung Tongkol, dan Kampung Lodan. KAKC merupakan wadah untuk menyalurkan aspirasi masyarakat, termasuk mewadahi kegiatan-kegiatan yang ingin dilaksanakan oleh warganya. Walaupun ke tiga kampung ini tergolong dalam kategori permukiman kumuh, masyarakatnya tidak menyerah dalam memperbaiki kualitas hidup, seperti melakukan kegiatan pemberdayaan masyarakat dibidang kebersihan, urban farming dengan pupuk komposer, pembuatan septic tank, dll. 


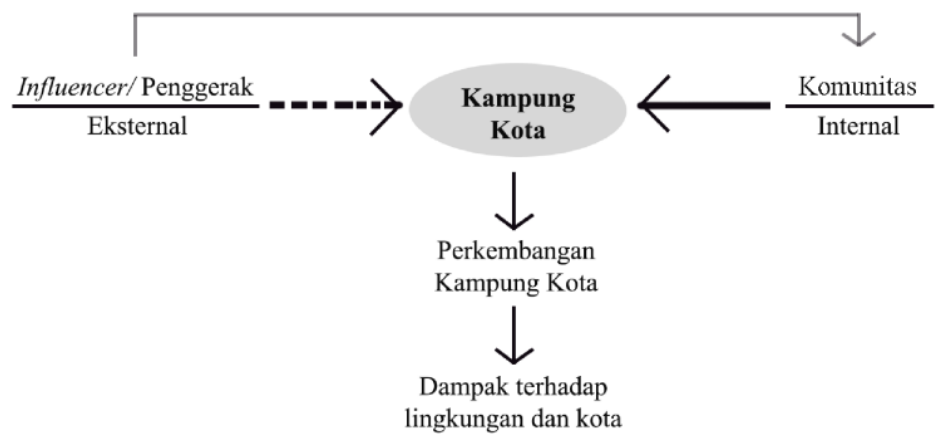

Gambar 5. Diagaram Proses Perkembangan Kampung

Sumber: Penulis, 2019

\section{Proses dan Hasil Perancangan Tapak}

Tapak dipilih karena melihat analisis potensi yang ada. Tapak berada pada lokasi yang dekat dengan kampung kota sekaligus dekat dengan daerah wisata, untuk mewujudkan gagasan mengenai pendorongan kegiatan ekonomi bagi kesejahteraan masyarakat kampung kota. Tapak juga dekat dengan salah satu museum (Museum Bahari) juga beberapa kampung kota yang masyarakatnya berpotensi menjadi penggerak kegiatan-kegiatan sosial. Kota tua dipilih karena merupakan daerah wisata yang cukup besar potensinya. Kota Tua Jakarta Utara masih sangat kental dengan suasana kolonial yang pada sejarah terbentuknya juga berhubungan dengan sejarah kampung kota di Jakarta.

\section{Batas dan Ukuran - ukuran pada Tapak}

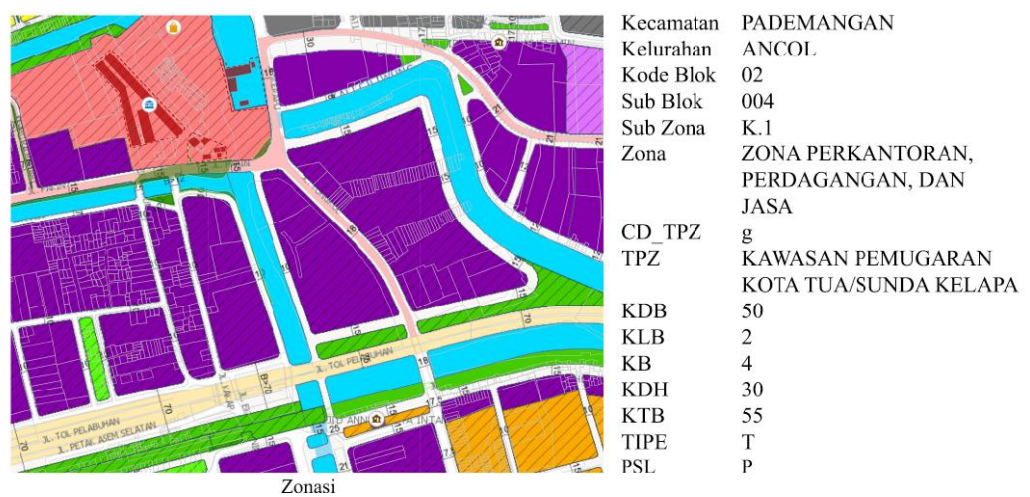

Gambar 6. Zonasi Tapak

Sumber : Jakartasatu.co.id

Lokasi berada pada Kawasan Wisata Kota Tua Jakarta, tepatnya pada Jalan Tongkol, Pademangan, Jakarta Utara. Jalan Tongkol termasuk dalam kategori Jalan Kolektor Sekunder, yaitu memiliki fungsi untuk pelayanan jasa distribusi masyarakat dalam kota. Jalan Tongkol menjadi akses jalur distribusi bagi daerah distribusi Jalan Lodan ke dalam Kota (Jakarta Barat atau Jakarta Pusat). Selain fungsi distribusi, Jalan Tongkol juga menjadi penghubung Area Wisata Kota Tua dari area Fatahillah ke Museum Bahari. Akses yang dilalui untuk menuju Museum Bahari dari Area Fatahillah adalah melalui jalur pedestrian atau kendaraan (kendaraan umum atau pribadi), bila menggunakan kendaraan umum, dapat menggunakan angkot ataupun kendaraan umum online (ojek online atau mobil online). Sedangkan untuk menuju Kawasan Wisata Kota Tua dapat dicapai dengan kereta, busway, angkot, ataupun bajaj. Jarak dari tapak ke tempat wisata terdekat adalah ke Museum Bahari yaitu sekitar $250 \mathrm{~m}$, sedangkan untuk ke wilayah Taman Fatillah adalah $700 \mathrm{~m}$. Tapak juga dekat dengan Pasar 
Asemka, yaitu berjarak $1100 \mathrm{~m}$. Selain dekat dengan tempat wisata, Tapak juga dikelilingi oleh Kampung Kota, yang terdekat adalah Kampung Kerapu, yaitu berjarak 100m, jika berjalan kaki dapat ditempuh dengan waktu kurang dari 5 menit.

Proses perancangan tidak luput dari hasil analisis tapak yang telah dibuat. Hal - hal utama yang diperhatikan dari hasil analisis tapak adalah akses masuk pedestrian ataupun kendaraan, ruang terbuka pada tapak, jalur pada tapak, titik kumpul, orientasi bangunan, dan juga bentuk bangunan itu sendiri. Posisi tapak potensial untuk menjadi penghubung (Linkage) antara kawasan kota tua dan Museum Kelautan Jakarta (Museum Bahari). Pada pengolahan tapak, akses masuk kedalam tapak dibuka menjadi beberapa bagian. Ada empat pada bagian muka, satu pada bagian samping, dan satu pada bagian belakang. Pada bagian muka, disediakan Market Place yang sifatnya semi permanen dan area Bazzar yang sifatnya non permanen untuk menyambut turis yang datang ke tapak. Area Market Place dibuat dinamis mengikuti bentuk tapak sehingga turis dapat tetap berjalan ke arah Museum Bahari.

Sedangkan untuk akses masuk mobil dan motor disediakan pada bagian belakang bangunan. Namun, tempat parkir yang disediakan terbatas hanya untuk pengguna produksi, sedangkan untuk turis atau pengunjung dapat menggunakan transportasi umum, berjalan kaki, atau menggunakan sepeda.

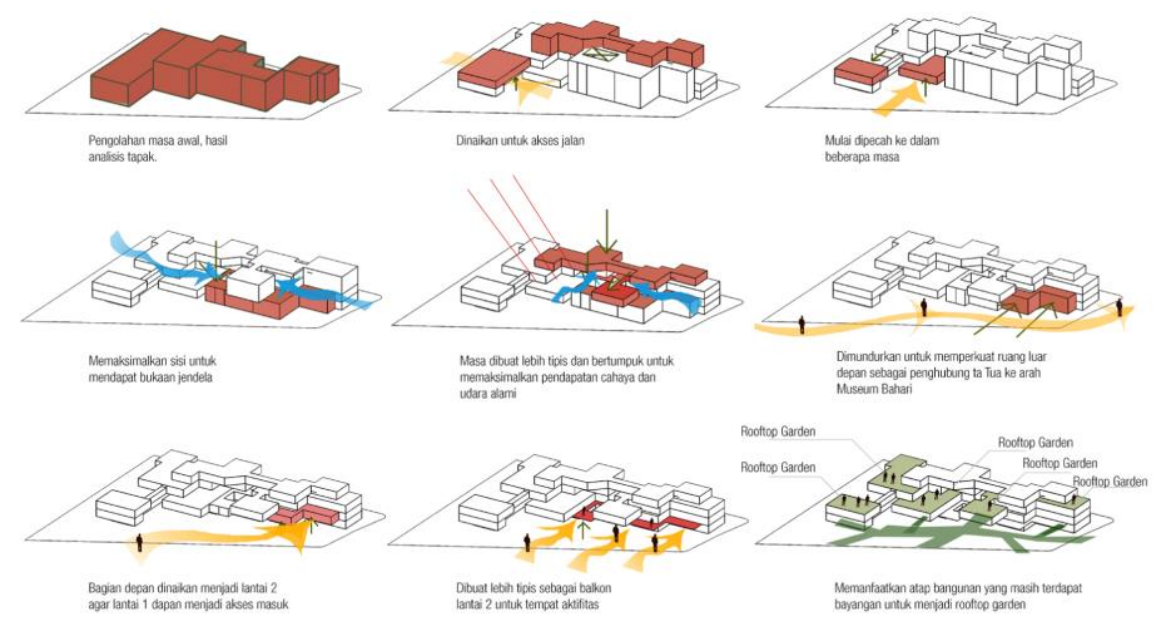

Gambar 7. Proses Transformasi Massa

Sumber: Penulis, 2019

Proses Transformasi masa juga dipengaruhi oleh kondisi tapak, seperti orientasi matahari dan posisi tapak terhadap konsep urban. Bukaan pada bangunan dimaksimalkan, masa yang bertumpuk diposisikan tidak sejajar agar setiap ruang mendapatkan cahaya matahari dan pengudaraan alami yang cukup. Pada bangunan juga diaplikasikan ruang-ruang hijau diatas bangunan untuk memaksimalkan konsep hijau dan juga sebagai sarana urban farming.

\section{Rancangan Bangunan}

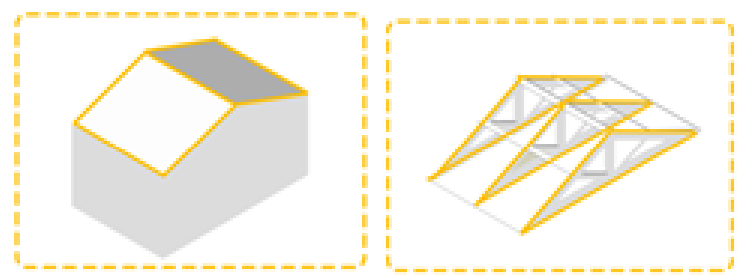

Gambar 8. Bentuk Atap

Sumber: Penulis, 2019 
Bentuk atap yang diaplikasikan adalah bentuk atap sederhana, berbentuk pelana seperti pada kampung kota dan umumnya ditemukan pada bangunan tradisional Indonesia. Atap yang dibentuk menggunakan material masa modern yang tidak terlalu mahal, yaitu menggunakan konstruksi baja ringan. Selain tidak mahal, juga mudah untuk dieksplorasi secara dinamis.

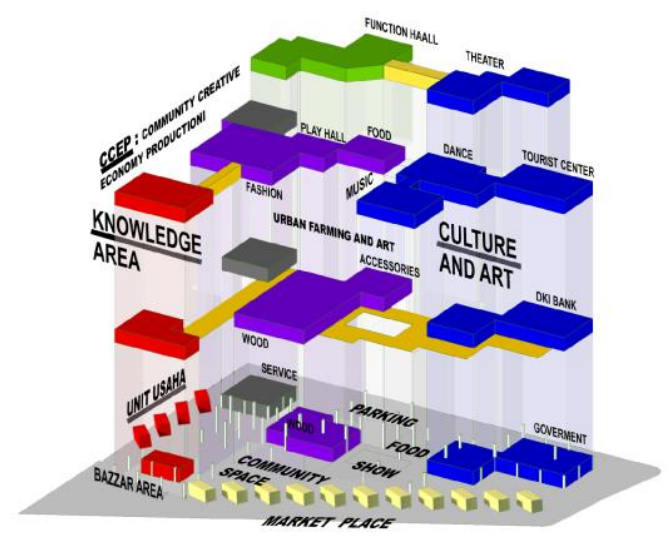

Gambar 9. Zoning Balai Kampung Kreatif Sumber: Penulis, 2019

Pada perancangan Bangunan Balai Kampung Kota Kreatif, zoning yang terbentuk adalah seperti pada Gambar 9. Pada Lantai dasar kegiatan-kegiatan yang difokuskan bersifat publik, lalu naik kelantai dua mulai privat sesuai sasarannya yaitu warga kampung kota dan turis. Pada masa sebelah kiri difokuskan untuk kegiatan komunitas warga kampung kota, segangkan bagian kanan dapat digunakan untuk kegiatan wisatawan, dan keduanya dipertemukan lagi pada lantai empat. Program-program yang disedikan perlantai dibedakan sesuai bidang yang dibutuhkan, seperti pada lantai dua, kegaitan produksi adalah kayu dan kriya sedangkan pada lantai dua adalah pakaian dan makanan.

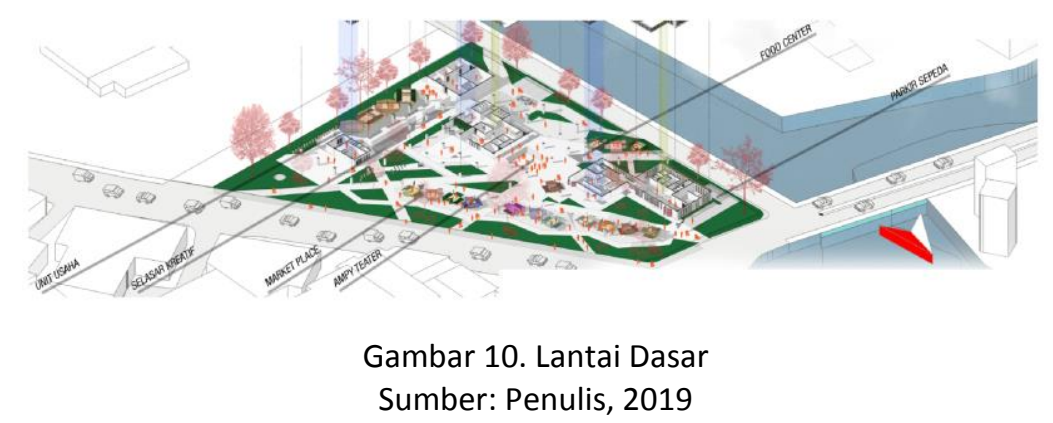

Pada lantai dasar kegiatan-kegiatan public yang difasilitasi trdapat pada beberapa program, yaitu Market Place, Ampy Theater, Food Center, dan Selasar kreatif, sedangkan zona semi privat adalah zona unit produksi milik warga yang memiliki fasilitas alat untuk mendukung produksi yang dilakukan komunitas. Pada lantai dasar terdapat beberapa akses masuk, pada bagian depan ada empat akses, akses pertama mengarah ke area bazzar, sedangkan tiga akses lainnya mengarah langsung ke Market Place dengan satu jalan utama langsung mengarah ke Ampy Theater. 


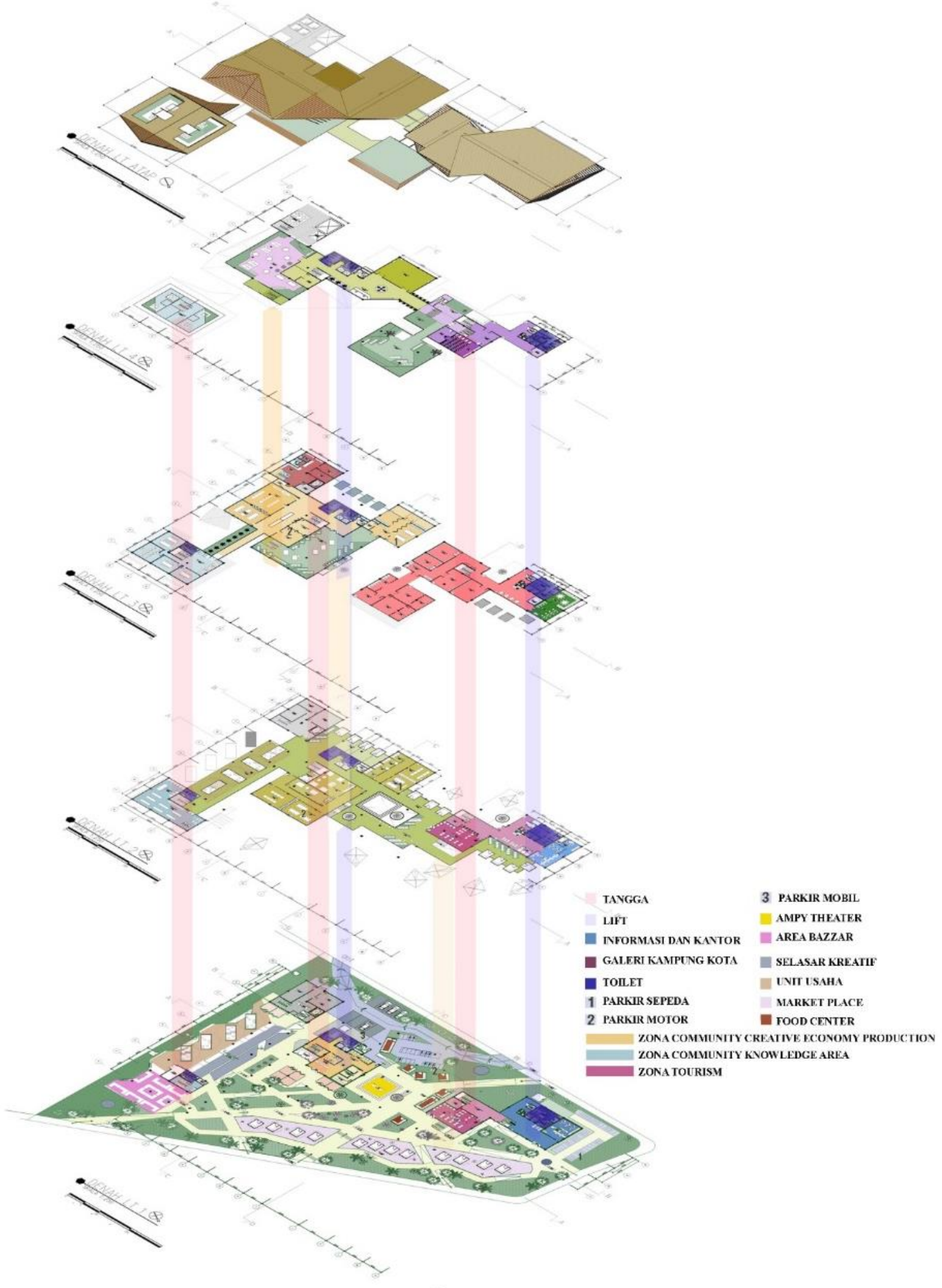

Gambar 11. Denah Exploded

Sumber: Penulis, 2019 
Untuk akses akses vertikal disediakan tangga dan lift. Tangga dan lift dari lantai satu dapat diakses dari dalam bangunan sehingga keamaan tetap terjaga, sedangkan beberapa tangga pada lantai dua dan tiga dapat diakses dari luar ruangan.

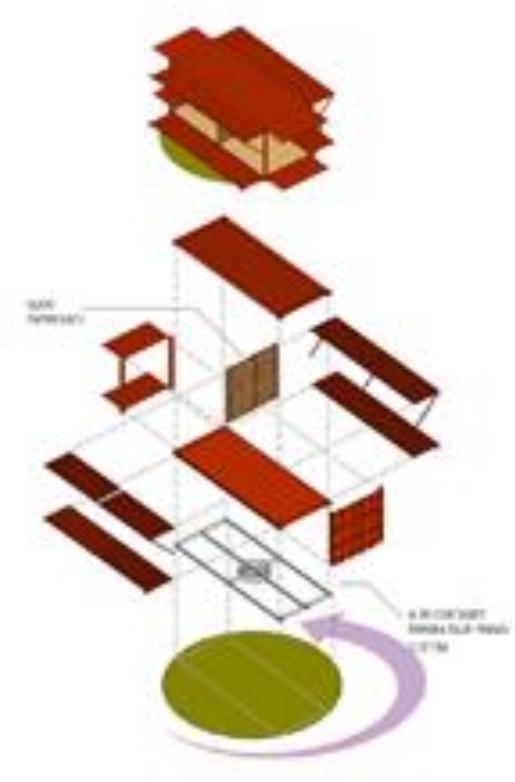

Gambar 11. Struktur Container Sumber: Penulis, 2019

Kontainer digunakan untuk unit usaha dan Market Place. Kontainer dipilih karena memiliki sifat portable dan fleksible. Kontainer bekas dimodifikasi untuk dapat diputar dan memiliki sumbu poros, sehingga dapat mengatur keadaan ruang luar nya, dapat menjadi semakin luas ketika kontaner diposisikan berbeda. Kontainer yang diputar juga berguna untuk mengubah suasana Balai Kampung Kreatif sesuai dengan sisi kontainer yang dapat dicat dengan gambargambar seni mural.

Pada Lantai dua dan seterusnya, kegiatan yang disediakan lebih privat dari pada lantai sebelumnya, namun tetap dapat dimasuki oleh pengunjung karena tujuan dari bangunan adalah tukar ilmu dan interaksi yang erat antar warga kota, warga kampung kota dan turis. Pada lantai dua disediakan juga balkon komunal sebagai jalur untuk berpindah masa dan kegiatan urban farming public. Pada balkon komunal juga diberikan void kebawah kearah ampy theater sehingga dapat menonton pertunjukan dari balkon. Pada lantai tiga terdapat tempat urban farming yang cukup besar yang merupakan atap dak dari lantai dua sehingga setiap ruang yang terdapat pada bangunan dapat dimanfaatkan dengan maksimal. Pada lantai empat ruang disediakan lebih komunal yaitu Community Function Hall yang dapat digunakan untuk rapat pertemuan antar warga, warga dan pemerintah, ataupun acara edukasi, dan juga resepsi pernikahan.

\section{Program Ruang}

Total luas lantai bangunan adalah $8086 \mathrm{~m} 2$. Luas tersebut terbagi atas empat lantai. Lantai pertama memiliki luas 2435 m2, lantai ke-dua 2435 m2, lantai ketiga memiliki luas 1944, dan lantai keempat memiliki luas $1272 \mathrm{~m} 2$. Luas tiap lantai tidak lah sama karena pada lantai-lantai atas (lantai dua, lantai tiga, dan lantai empat) terdapat pemanfaatan area dak beton lantai sebelumnya untuk digunakan sebagai ruang kegiatan, seperti urban farming pada lantai tiga pada bangunan. 
Tabel 1.Program Ruang

\begin{tabular}{|l|c|c|c|c|}
\hline \multicolumn{1}{|c|}{ NAMA RUANG } & LUAS & KAPASITAS & JUMLAH & $\%$ dari total luas \\
\hline MARKET PLACE :CONTAINER) & 79.2 & 55 & 11 & 0.024 \\
\hline CREATIVE ENTREPRENEUR UNIT (CON- & 157 & 52 & 13 & 0.047 \\
\hline GALLEY & 374 & 50 & 2 & 0.113 \\
\hline TOURIST CENTER & 72 & 10 & 1 & 0.02 \\
\hline THEATER & 48 & 40 & 1 & 0.16 \\
\hline COMMUNITY FUNCTION HALL & 108 & 120 & 1 & 0.03 \\
\hline CULTURE \& ART - RUANG TARI & 186 & 50 & 5 & 0.06 \\
\hline CULTURE \& ART - RUANG MUSII & 60 & 10 & 2 & 0.018 \\
\hline CKA : LBRARY & 144 & 60 & 1 & 0.04 \\
\hline CKA : DISCUSSION ROOM & 36 & 20 & 1 & 0.01 \\
\hline CKA : WORKSHOP ROOM & 60 & 80 & 4 & 0.018 \\
\hline CEP : MAKER SPACE ROOM & 606 & 150 & 8 & 0.18 \\
\hline CEP : WORKSHOP ROOM & 216 & 120 & 4 & 0.06 \\
\hline BAZZAR AREA & 144 & 80 & 1 & 0.03 \\
\hline FOOD \{CONTAINER\} & 34.5 & 20 & 5 & 0.01 \\
\hline URBAN FARMING AREA & 288 & 40 & 7 & 0.06 \\
\hline PLAY HALL & 252 & 40 & 1 & 0.07 \\
\hline MUSHOLLA & 51 & 20 & 2 & 0.015 \\
\hline TOILET & 396 & 70 & 11 & 0.12 \\
\hline STORAGE \& GUDANG & 190 & - & 15 & 0.06 \\
\hline SERVICE AREA & 216 & - & 6 & 0.065 \\
\hline
\end{tabular}

Sumber: Penulis, 2019

Dari hasil perancangan yang telah dibuat, luasan-luasan yang dipakai oleh bangunan tidak terlalu besar perbedaan luasnya satu sama lain. Hal ini dikarenakan ingin tercapainya keseimbangan antara aktifitas-aktifitas dari komunitas ataupun turis. Namun, tetap terdapat luas ruang yang terbesar adalah Ruang Maker Space, karena membutuhkan ruang bagi peralatan dan mesin. Ruang-ruang dirancang secara efektif agar tidak ada ruang yang terbuang atau bersifat negatif (tidak terpakai). Ruang yang tidak terlalu besar juga berguna untuk membentuk suasana ruang yang lebih intim diantara para penggunanya.

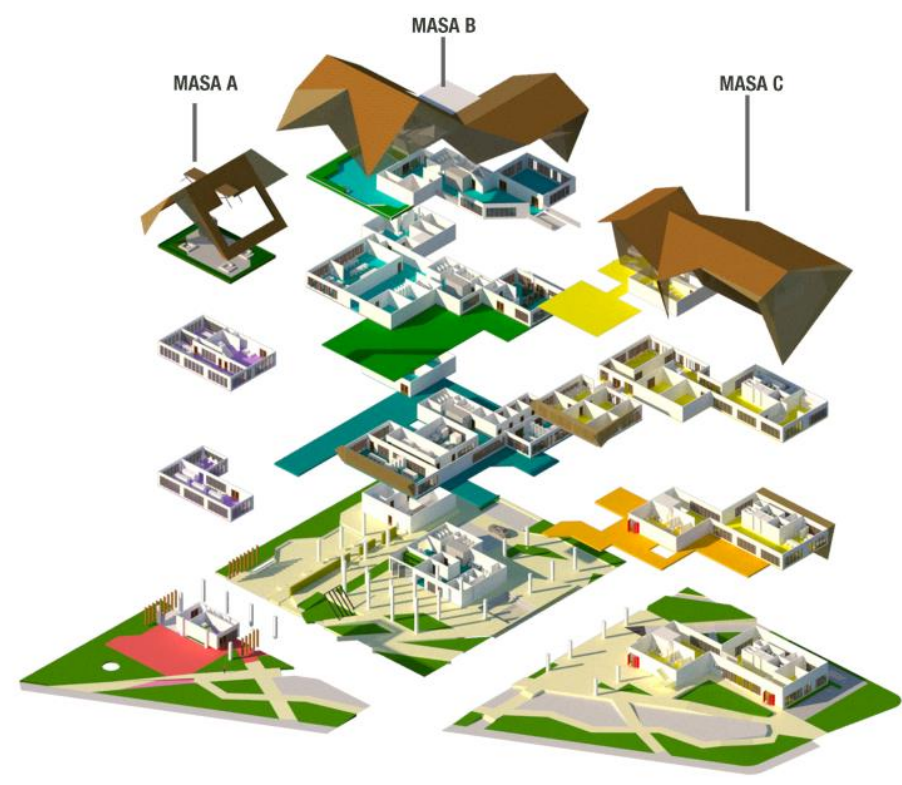

Gambar 12. Pembagian Masa

Sumber: Penulis, 2019

Bangunan Balai Kampung Kreatif dibagi menjadi tiga massa utama yaitu massa A, massa $B$, dan massa C. Pada setiap masa konsentrasi program berbeda-beda. Massa A adalah Knowledge area, yaitu area untuk kegiatan belajar yang sifatnya lebih formal, seperti perpustakaan, ruang kelas, dan ruang computer. Sedangkan untuk Massa B, kegiatan yang 
difokuskan adalah kegiatan industry kreatif, yaitu pelatihan-pelatihan dalam bidang industri kreatif pakaian, kayu, kerajinan tangan kecil, dan tanaman. Masssa $\mathrm{C}$ difokuskan untuk turis, program yang disediakan adalah Tourist Center, Galeri, dan Theater. Antar masa dihubungkan oleh jembatan dan balkon komunal.

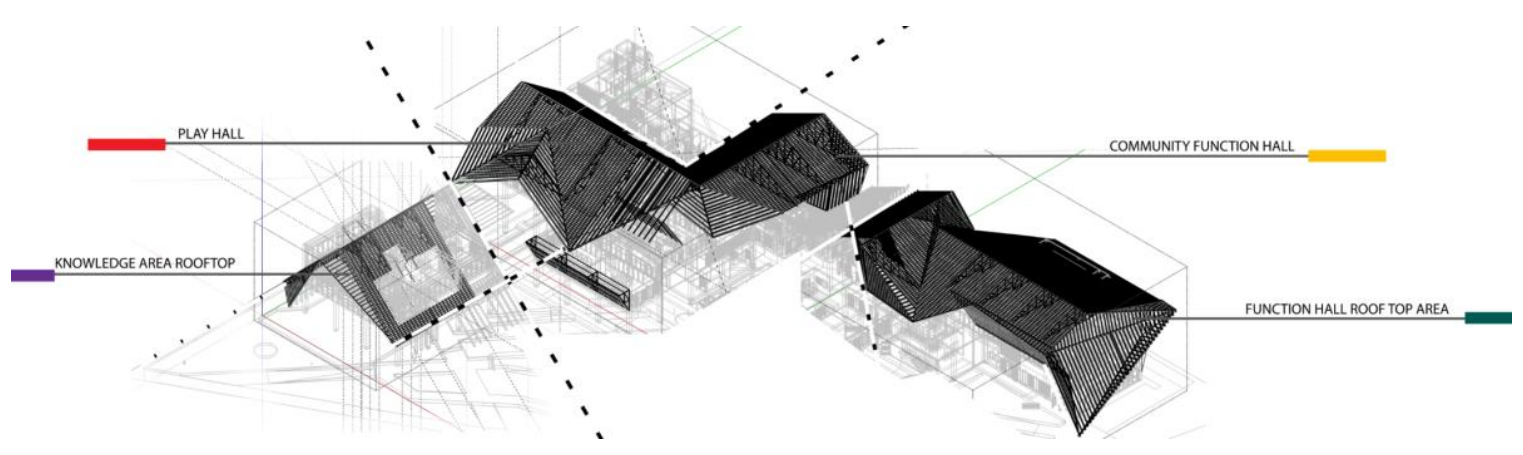

Gambar 13. Atap Balai Kampung Kota Kreatif Sumber: Penulis, 2019

Pada perancangan ada beberapa tempat yang turut memperlihatkan atap untuk mendukung estetika dan suasana ruang yang lebih tinggi. Diantaranya adalah ruang Community Function Hall, Play Hall, dan Knowledge Area Rooftop.

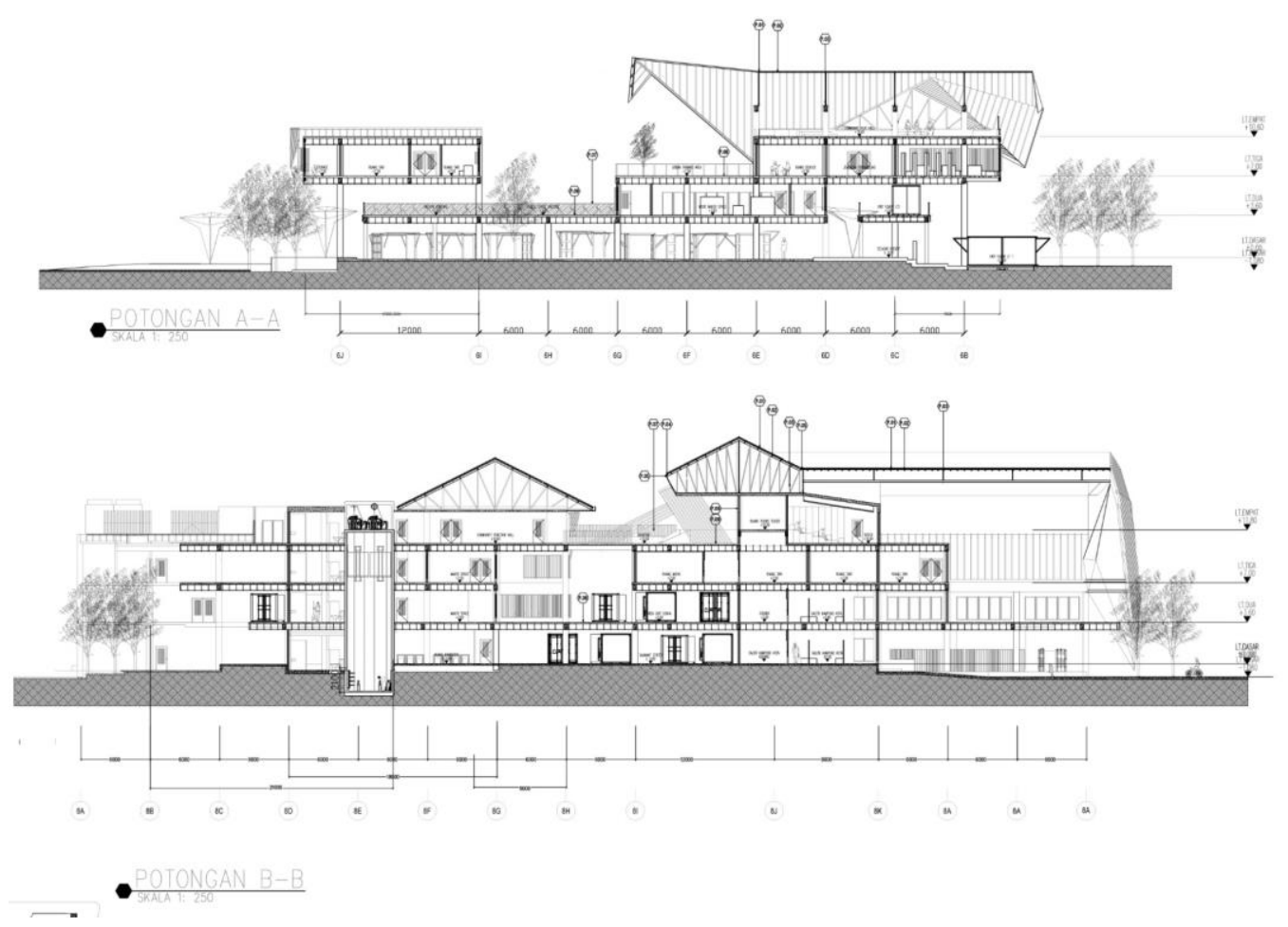

Gambar 14. Potongan Melintang Bangunan Sumber: Penulis, 2019

Desain tidak hanya mementingkan ruang dalam, namun juga ruang luar. Pada ruang luar difokuskan untuk memfasilitasi kegiatan interaksi manusia, tenaman hijau dan kegiatan Urban Farming. Kegiatan urban farming didukung oleh alat - alat hidroponik yang dapat diaplikasikan juga di kampung kota dan tidak membuhkan lahan yang luas. Tanaman yang dibudidaya juga menggunakan pot-pot kayu atau seng agar ketika diaplikasikan di kampung kota tidak memakan lahan luas. 


\section{Fasad Bangunan}

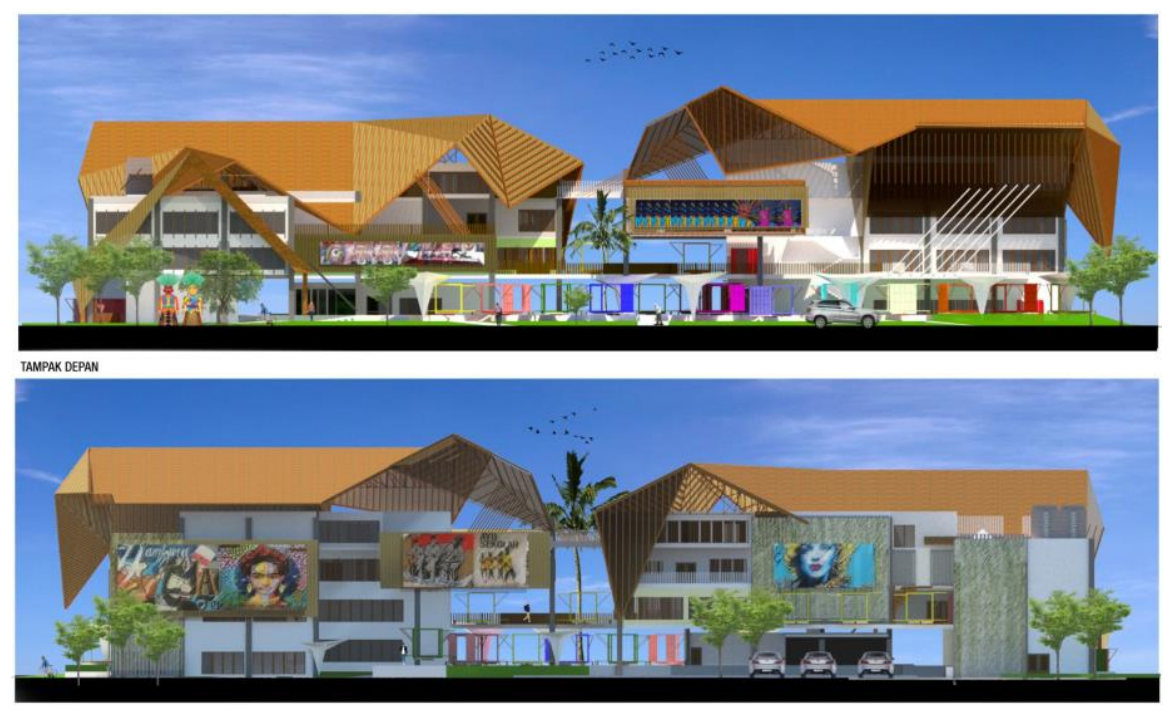

TAMPAK BELAKANG

Gambar 15. Tampak Depan dan Belakang Sumber: Penulis, 2019

Tampak bangunan dibuat juga interaktif. Pada fasad bangunan disediakan tempat untuk memanjang hasil mural yang telah dibuat oleh komunitas sehingga fasad bangunan yang tercipta lebih interaktif dan dirasa milik seluruh warga pengguna. Fungsi dari fasad yang interaktif ini juga sekaligus untuk mengundang pengunjung karena estetika yang menarik.
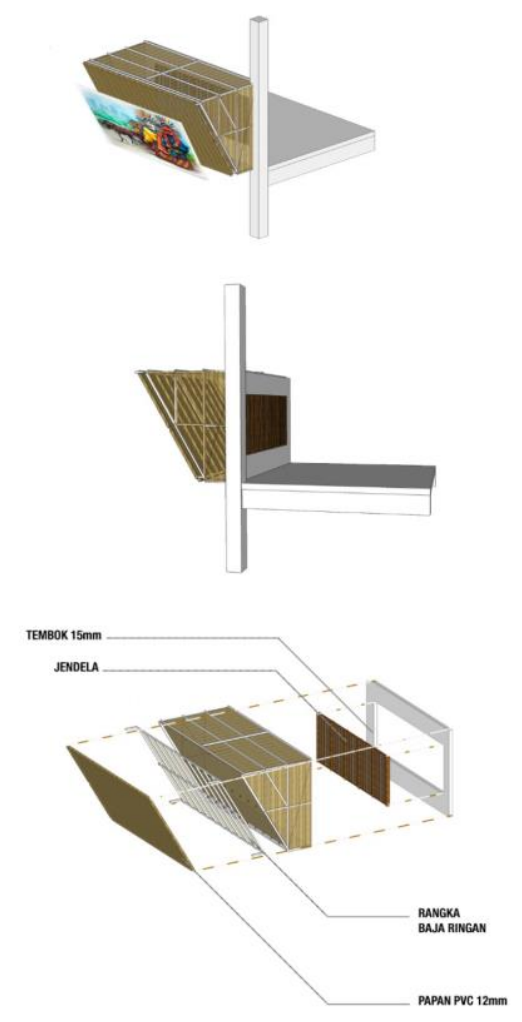

Gambar 16. Detail Fasad Second Skin Sumber: Penulis, 2019 


\section{KESIMPULAN DAN SARAN}

Kesimpulan yang didapat pada perancangan Balai Kampung Kota Kreatif adalah sebuah bangunan dapat berisi dua program yang digabungkan dengan sasaran yang berbeda sekaligus dengan cara mewadahi kebutuhan ruang untuk keduanya secara seimbang. Dengan menggabungkan kedua sasaran sekaligus, interaksi yang terjadi didalam bangunan akan semakin kuat. Namun, khususnya sifat-sifat yang terkait dengan sasaran pengguna bangunan juga perlu diperhatikan dalam hal warga kampung kota milenial memiliki sifat fleksible, maka ruang-ruang yang dirancang jg harus memenuhi sifat tersebut, atau turis milenial yang bersifat eksploratif membutuhkan ruang-ruang yang dapat mengembangkan sifat eksplorasi mereka seperti Ampy Theater dan Galeri Kampung Kota.

\section{REFERENSI}

Binar. (2018). 7 Wisata Kampung Tematik di Malang, Punya View Instagramable $<$ https://www.idntimes.com/travel/destination/binar-restu-bumi/7-wisata-kampungtematik-di-malang-punya-view-instagramable-exp-c1c2/full;. (Disarikan dari berbagai sumber).

Darrundono. (2007). Peran Modal Sosial Dalam Perbaikan Kampung. Studi Kasus: Proyek Muhammad Husni Thamrin di Jakarta. Disertasi Program Pascasarjana Kajian Ilmu Lingkungan, Universitas Indonesia. Jakarta (tidak diterbitkan)

Hidayat, R. (2016). Memotong rumah dan tinggal seatap dengan 20 orang agar tidak digusur. Diakses 25 maret 2018<https://www.bbc.com/indonesia/majalah-38279822

Mantiri, H. J. dan Makainas. (2011). Eksplorasi Terhadap Arsitektur Dekonstruksi. Media Matrasain. Vol.8 No.2 Agustus 2011.

Novielle. J. (2007). Theoretical Exploration. University of Pretoria etd.

PEMPROV DKI. (2017) Guidelines Kota Tua, Jakarta: PEMPROV DKI Dinas Kebudayaan dan Permusiuman

TKI MAI 33 Jakata. (2017) Kampung Kota Jakarta. Jakarta : FK MAJ

Roihanah, Ita. (-). Derrida dan Proses Kreatif Bernard Tchumi. Public Administration.

Rossi, A. (1981)"The Architecture of the City". New York : The MIT Press.

Rujak RCUS (2018), 100 Kompendium Kampung Kota Jakarta. Jakarta : RUJAK.

Simone, A. M., and Achmad U. F. (2013). "On the way to being middle class: The practices of emergence in Jakarta.". Jakarta

Yasemin D. G.(2007) "Type and typology in architectural discourse", Temmuz. Department of Architecture Çağış BALIKESĐR 